\title{
Investigating Air Quality and Air-related Complaints in the City of Tshwane,
}

\section{South Africa}

\author{
C. Wright ${ }^{1 *}$, M.A. Oosthuizen ${ }^{1}$, J. Mostert ${ }^{2}$ and L. Van Niekerk ${ }^{3}$
}

\author{
${ }^{1}$ Environmental Health Research Group, CSIR Natural Resources and the Environment, Pretoria, South Africa. \\ ${ }^{2}$ Environmental Management, City of Tshwane, Pretoria, South Africa. \\ ${ }^{3}$ Municipal Health Services, City of Tshwane, Pretoria, South Africa. \\ * Corresponding author. Email: cwright@csir.co.za; Tel: +27 12841 3092; PO Box 395, Pretoria, 0001, South
}

Africa.

\begin{abstract}
To determine the impact of implemented air quality interventions beyond ambient air pollution reductions, indicators need to be identified and appropriate health data need to be routinely collected to track airrelated health. Presently, the only regulated environmental health performance indicator routinely collected as part of air quality management is the air-related complaint lodged by the public. Here, five years of air-related complaints $(n=875)$ made by residents in the City of Tshwane (Pretoria, Gauteng) were analysed and considered in relation to ambient $\mathrm{SO}_{2}$ and $\mathrm{PM}_{10}$ concentrations monitored at permanent air quality monitoring stations. When considering exceedances of the National Ambient Air Quality Standards, there were 17 complaint days with either an $\mathrm{SO}_{2}$ or $\mathrm{PM}_{10}$ daily average concentration exceedance. However, it was very difficult to make meaningful conclusions about the relation between ambient $A Q$ and air-related complaints given social, economic and data challenges and constraints. There is a real need to have local, air-related health data, for example, upper and lower respiratory tract infections, asthma, etc, generated at clinics and hospitals delivered directly and on an on-going, continuously updated basis to those responsible for implementation of air quality management plans.
\end{abstract}

Keywords: Air-related complaints, air quality, human health, South Africa

\section{Introduction}

A growing number of studies show that the largest burden of air pollution-related diseases is on developing countries where air pollution levels are also among the highest in the world (Krzyzanowski, and Cohen, 2008). Air pollution may cause symptoms ranging from eye, nose and throat irritation (Pan et al., 2010), exacerbation of asthma (Koenig, 1999) and reduced lung function (WHO, 2005) to cardiovascular symptoms such as high blood pressure (Brook et al., 2010) and lung cancer (Cohen and Pope, 1995). There is also a statistically-significant association between air pollution and mortality from respiratory and cardiovascular illnesses (Krzyzanowski, and Cohen, 2008).

In South Africa, air quality management has gone through substantial changes in the past 6 years. In 2010, the National Environmental Management: Air Quality Act No 39 of 2004
(RSA, 2004) officially replaced the Atmospheric Pollution Prevention Act No 45 of 1965 (RSA, 1965). The new Act shifted the focus from centralisation of air pollution governance to the decentralisation of power, placing the responsibility of air quality management on local authorities.

The City of Tshwane (Pretoria) is one of three large metropolitan areas (the others being Johannesburg and Ekurhuleni) in the Gauteng Province. In 2006, the Air Quality Management Plan for the City of Tshwane, developed by the Environmental Management Division and Municipal Health Services of the City, was approved. The plan is being used as a management and performance-monitoring tool for air quality (AQ) and to provide a baseline assessment of $A Q$ issues in the City. The Environmental Management Division maintains a network of five permanent and several semipermanent (i.e. street boxes) ambient $A Q$ and 
meteorological monitoring stations around the City. These stations are strategically located to monitor ambient levels of priority pollutants, namely, particulate matter (PM), sulphur dioxide $\left(\mathrm{SO}_{2}\right)$, ozone $\left(\mathrm{O}_{3}\right)$, volatile organic compounds (VOCs), carbon monoxide (CO) and nitrogen oxides (NOx) from known and unknown sources in different areas of the City. An air Quality Officer monitors and assesses ambient $A Q$ concentrations at these stations in accordance with the National Ambient Air Quality Standards that came into effect in 2009 (DEA, 2009).

Municipal Health Services of the City of Tshwane comprises Environmental Health Practitioners (EHPs) whose duties are defined by the National Health Act No 61 of 2003 (RSA, 2003). EHPs are responsible for the function of municipal environmental health services which include environmental pollution control. They are responsible for identifying air pollution agents and sources, and ensuring clean and safe air externally (ambient and from point sources) through emission inventory monitoring, modelling and toxicological reports (responsibilities shared with Environmental Management), reviews and complaints investigations (Government Gazette, 2009).

While activities to monitor ambient $A Q$ and introduce appropriate interventions for air pollution reduction are underway, human health surveillance is presently not an integrated part of air quality management in the City, or South Africa, although National Ambient Air Quality Standards were derived from international epidemiological studies of personal exposure. To ascertain the impact of implemented interventions beyond ambient air pollution reductions, indicators need to be identified and appropriate health data need to be routinely collected and made available to AQOs and EHPs. Presently, the only routinely-collected indicator of the impact of air pollution on the public is air-related complaints lodged by residents of the City to Municipal Health Services. Previous studies have considered using air-related complaints as an indicator of air pollution emissions (Evendijk et al., 1980), environmental pollution (Dasgupta and Wheeler, 1996), and annoyance from traffic noise and air pollution (Klaeboe et al., 2000). To the best of our knowledge, air-related complaints have been considered to identify air pollution sources specific to a complaint (Cadman et al., 1997) but have not been considered in light of the publics' experience of $A Q$ impacts in South Africa.
This paper reports on the analysis of 5 years of air-related complaints lodged by residents of the City of Tshwane. The nature and geographical location of these complaints were considered in relation to ambient $A Q$ monitored at the $A Q$ monitoring station nearest to the complainant's residential suburb. While the intention of this study was to explore the applicability and usefulness of using air-related complaints as an indicator of the public's experience of air pollution, several policy messages and suggestions for improvements to $A Q$ and public health monitoring and reporting practices also became apparent and are mentioned.

\section{Materials and Methods}

\section{Air-related complaints}

Public complaints captured routinely by EHPs about odours, visible air pollution and symptoms perceived to be related to air pollution or air pollution incidents for 1 January 2005 to 31 December 2009 were obtained from Municipal Health Services of the City. For each complaint made, the date, region in the City, residential suburb and air-related complaint category were captured. The City comprises eight zones commonly collapsed into five regional administrative zones, known as North-West, North-East, Central-West, East and South. All residential suburbs were categorised by the EHPs into one of the five regional zones depending on their location. The air-related complaints' categories used in this study were identical to those applied to the raw, detailed complaints by the City.

\section{Ambient $A Q$ monitoring and wind direction}

Permanent $A Q$ and meteorological monitoring stations are located in four of the five regional administrative zones in the City. The stations are Booysens (Central-West), Pretoria West (Central-West), Rosslyn (North-West), Mamelodi (East), and Olievenhoutbosch (South) (Figure 1). The City of Tshwane is dissected with one large mountain range, Magaliesberg, and several smaller ranges which may affect air pollution dispersion under certain conditions and influenced the locating of monitoring stations. Of all the priority pollutants identified by the National Department of Environmental Affairs (RSA, 2009), $\mathrm{SO}_{2}$ and $\mathrm{PM}_{10}$ were the two pollutants measured across all permanent sites; hence these pollution concentrations were used in this study. AQ data were provided by the Environmental Management Division of the City of Tshwane and the South African Air Quality Information System (SAAQIS). Data were available for 1 January 2009 to 31 December 
2009. $\mathrm{SO}_{2}$ concentrations were measured using API Model 100A and Thermo 43i instruments. $\mathrm{PM}_{10}$ concentrations were measured using Thermo FH 62 C14 Continuous Particulate Monitor and Tapered Element Oscillating Microbalance (TEOM) instruments. Annual average concentrations were used to compare $\mathrm{SO}_{2}$ and $\mathrm{PM}_{10}$ across all sites. Daily average concentrations were applied to understand ambient $\mathrm{AQ}$ conditions, specifically, $\mathrm{SO}_{2}$ and $\mathrm{PM}_{10}$ concentrations, on days when air-related complaints were lodged. Wind direction measured at the Eendracht meteorological monitoring station was used to understand whether ambient $A Q$ measured at a particular station was a reasonable estimate of the ambient $A Q$ experienced by the complainant in their residential suburb (data not shown).

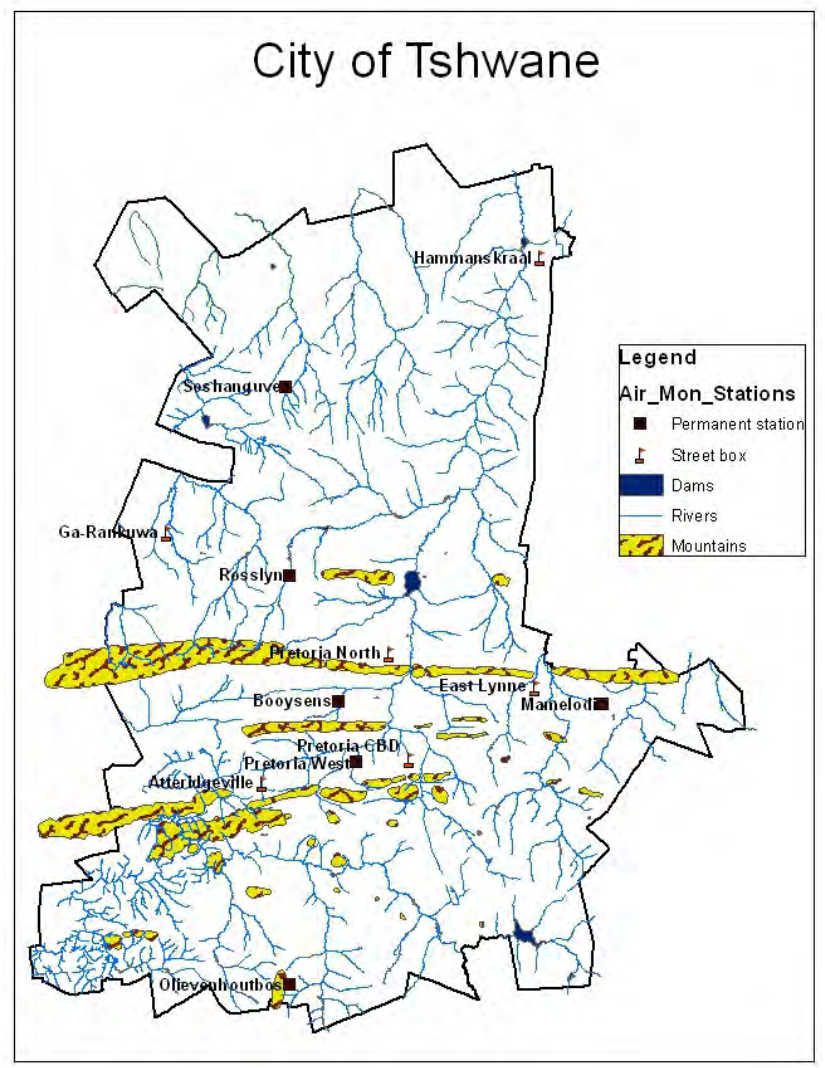

Figure 1. Physical map of the City of Tshwane showing the permanent $A Q$ monitoring stations (square markers) used in this study.

\section{Analyses}

Air-related complaints were analysed by year, region and type of complaint. Ambient $\mathrm{SO}_{2}$ and $\mathrm{PM}_{10}$ annual and daily average concentrations were analysed by $A Q$ monitoring stations. Exceedances of the National Ambient Air Quality Standards were identified. Using Geographical Information Systems, the air-related complaints were mapped in relation to the permanent $A Q$ monitoring stations. Air-related complaints were compared with ambient $\mathrm{SO}_{2}$ and $\mathrm{PM}_{10}$ daily average concentrations recorded at the nearest permanent monitoring station for the day on which the complaint was made. Wind direction recorded at the $A Q$ monitoring station was considered to provide insight into the applicability of using the nearest $A Q$ monitoring station as a proxy for ambient $A Q$ experienced by the complainant. For 2009, air-related complaints made on days when $\mathrm{SO}_{2}$ and $\mathrm{PM}_{10}$ daily average concentrations were in exceedance of National Ambient Air Quality Standards were isolated and analysed separately. These results are discussed bearing in mind data shortages and limitations.

\section{Results}

\section{Air-related complaints}

From 1 January 2005 to 31 December 2009, a total of 875 air-related complaints were lodged by members of the public to the City of Tshwane Municipal Health Services. The number of complaints per year was 207 (in 2005), 198 (2006), 223 (2007), 155 (2008) and 92 (2009). Five years is insufficient time to consider long term trends. A linear trend line fit gave $y=-27.3 x$ $+54966\left(R^{2}=0.6687\right)$ indicating a relatively poor fit, despite detecting a slight negative trend.

Figure 2 shows the type of air-related complaints as a percentage of the total complaints made between January 2005 and December 2009. The largest percentage of complaints were made about the presence of open fires $(27.5 \%)$, followed by spray-painting fumes $(20.4 \%)$ and dust $(17.3 \%)$. Backyard fires $(8.9 \%)$, fumes (unspecified source) (9.4\%) and smoke (2.6\%) were also reported.

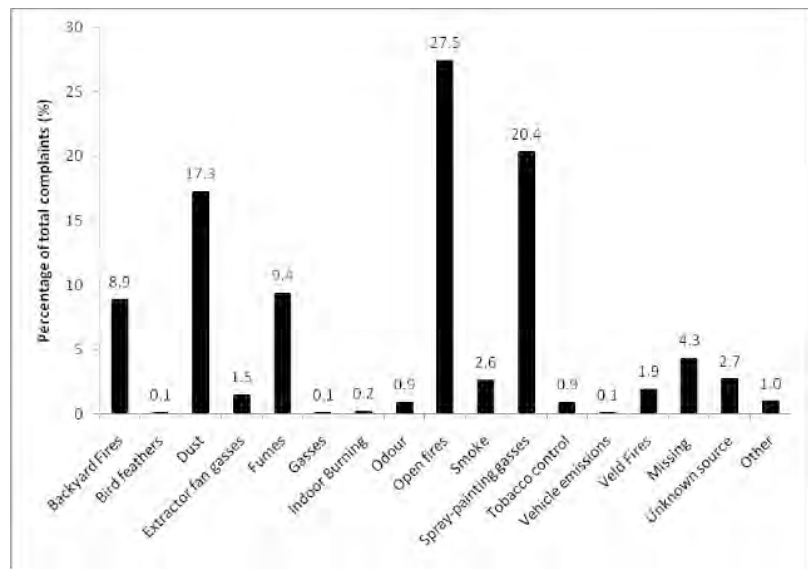

Figure 2. Type of air-related complaint as a percentage of the total complaints made from January 2005 to December 2009 ( $n=875)$. 
Air-related complaints were grouped by suburb into one of each of the five regional administrative zones and represented spatially in Figure 3 by ranking zones according to total number of complaints. The North-East and North-West zones had the least number of complaints over the past 5 years, with 55 and 98 complaints, respectively. The most number of complaints were lodged in the Central-West $(n=$ $275)$ and East $(n=289)$ zones. The South had an average number of complaints $(n=158)$ compared to the other four zones. The type and number of complaints by regional administrative zone were analysed to understand where specific types of complaints were most frequently reported (Figure 4).

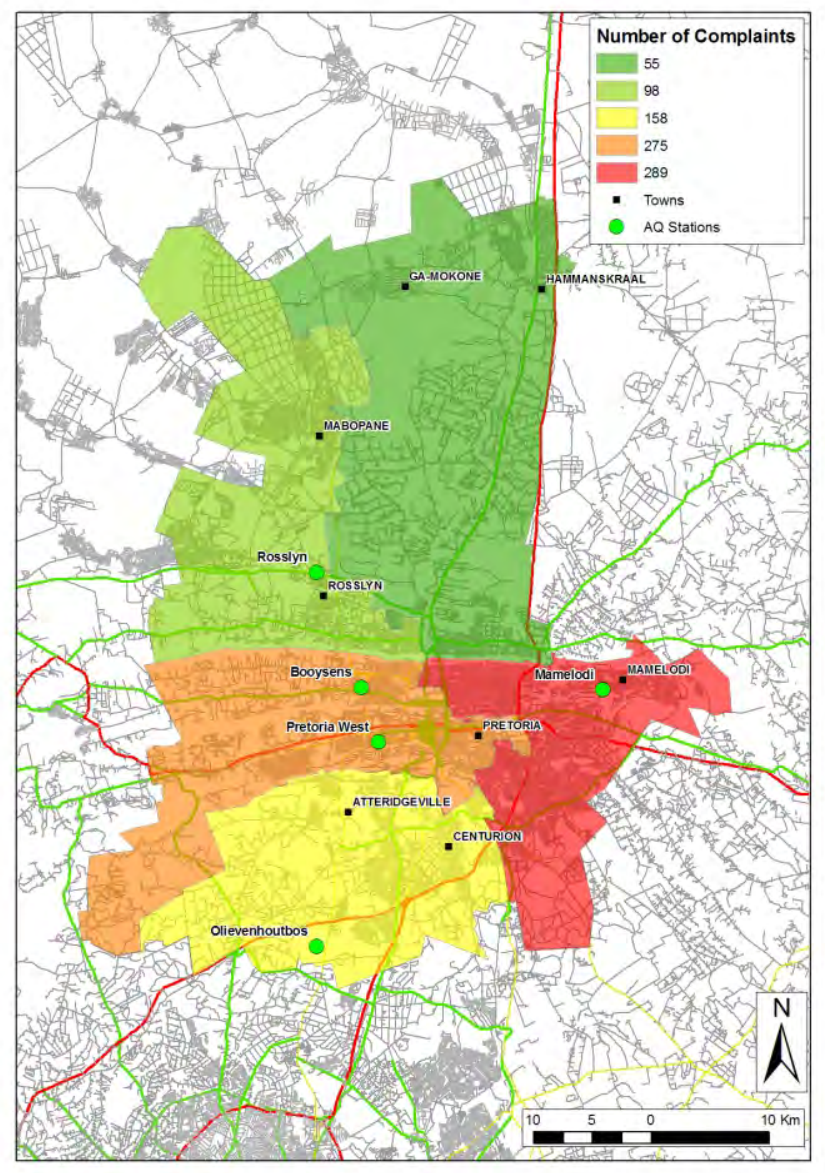

Figure 3. Total air-related complaints for $2005-2009$ $(\mathrm{n}=875)$ by City of Tshwane's five regional administrative zones: North-West, North-East, Central-West, East and South. Locations of permanent $A Q$ monitoring stations are shown with green circles and black rings.

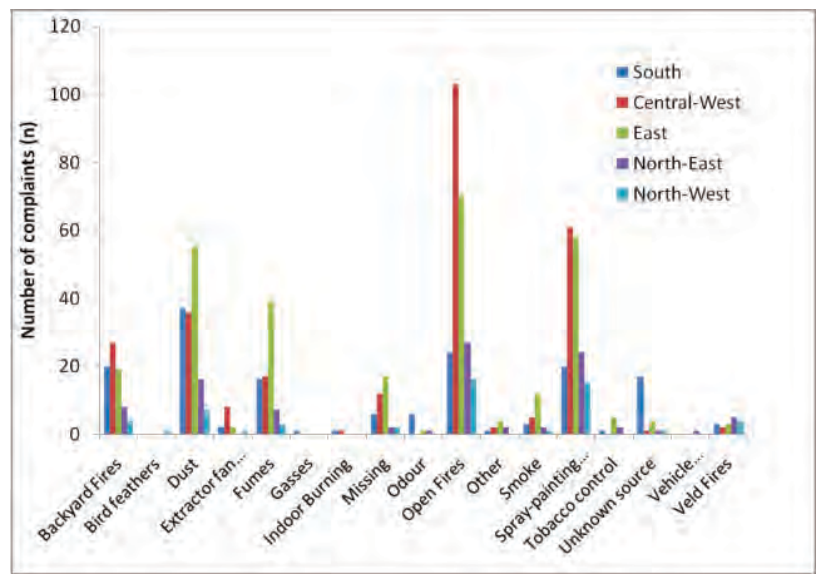

Figure 4. Type and number of air-related complaints for $2005-2009$ by regional administrative zone in the City of Tshwane. ('Incomplete' category was combined with 'Missing' category.)

For the top-five most commonly reported airrelated complaints, i.e. backyard fires, dust, fumes, open fires and spray-painting gasses, the Eastern zone consistently tended to have among the most number of complaints relative to all other zones. For backyard fires, several complaints were made in the Central-West and Southern zones too. Dust and fumes were also commonly reported in the Southern and CentralWest zones. The largest proportion of complaints regarding open fires and spraypainting gasses was for the Central-West. A large number of complaints about open fires and spray-painting gases were also made in the North-East zone. Interestingly, the most number of 'unknown source' complaints and nearly three times that of any other zones were made by the public living in the South. The highest number of complaints by type in the North-West zone was for open fires and spray-painting gasses.

\section{Ambient air quality at the permanent $A Q$ monitoring stations}

Air quality data for all five permanent $A Q$ monitoring stations were available for 2009. Table 1 provides the annual average $\mathrm{SO}_{2}$ and $\mathrm{PM}_{10}$ concentrations for each station and the National Ambient Air Quality Standards for each of these priority pollutants. There was no permanent $A Q$ monitoring station in the NorthEastzone.

The highest annual average $\mathrm{SO}_{2}$ and $\mathrm{PM}_{10}$ concentrations were found at the Pretoria West and Olievenhoutbosch $\mathrm{AQ}$ monitoring stations, respectively. The annual average $\mathrm{SO}_{2}$ concentration for Pretoria West was also higher than the National Ambient Air Quality Standard of 
$19 \mathrm{ppb}$. For $\mathrm{PM}_{10}$, annual average concentrations exceeded the National Ambient Air Quality Standard of $50 \mathrm{\mu g} \mathrm{m}^{-3}$ at all stations, except for Rosslyn, with the difference in concentration exceedances ranging from $1 \mu \mathrm{g} \mathrm{m}$ ${ }^{3}$ to $42 \mu \mathrm{g} \mathrm{m}^{-3}$.

Figure 5 and Figure 6 show the daily average $\mathrm{SO}_{2}$ and $\mathrm{PM}_{10}$ concentrations for 2009 for the five permanent $A Q$ monitoring stations, respectively. Daily average $\mathrm{SO}_{2}$ exceedances (greater than $48 \mathrm{ppb})$ were recorded at Pretoria West $(n=38)$ and Rosslyn $(n=6)$. Daily average $\mathrm{PM}_{10}$ exceedances (greater than $120 \mathrm{\mu g} \mathrm{m}^{-3}$ ) were recorded at Booysens $(n=85)$, Mamelodi $(n=$ $70)$, Olievenhoutbosch $(n=84)$, Pretoria West $(n$ $=43$ ) and Rosslyn $(n=13)$. The National Ambient Air Quality Standards only allow for four exceedances of the 24-hour standard per annum. It is thus evident that, for $\mathrm{SO}_{2}$, the Pretoria West and Rosslyn AQ monitoring stations did not comply. Most exceedances happened between April and August, the winter season, when domestic coal burning normally increases, coinciding with conditions highly conductive to the formation of inversions. These inversion layers have an influence on the dispersion potential of air pollution. The Pretoria West $A Q$ monitoring station consistently showed the highest $\mathrm{SO}_{2}$ levels compared to all of the monitoring stations in Tshwane (Figure 5). The exceedances at the Rosslyn $A Q$ monitoring station occurred during mid-winter. Concentrations of $\mathrm{PM}_{10}$ exceeded the 24-hour guideline more than four times at all of the $A Q$ monitoring stations (Figure 6). Roughly two peaks may be identified: one peak is evident at the beginning of the year (about January and February) and another from about April to August (wintertime). The Booysens $A Q$ monitoring station recorded the most number of exceedances (85) for 2009. Most of the exceedances at Booysens happened during the first two months of 2009.

Table 1. Annual average $\mathrm{SO}_{2}(\mathrm{ppb})$ and $\mathrm{PM}_{10}\left(\mu \mathrm{g} \mathrm{m}^{-3}\right)$ concentrations for the five permanent $\mathrm{AQ}$ monitoring stations in the City of Tshwane.

\begin{tabular}{|c|c|c|c|c|c|}
\hline $\begin{array}{l}\text { AQ monitoring } \\
\text { station }\end{array}$ & Regional zone & $\begin{array}{l}\mathrm{SO}_{2} \\
(\mathrm{ppb})\end{array}$ & $\begin{array}{c}\mathrm{SO}_{2} \text { National } \\
\text { standard } \\
(\mathrm{ppb})\end{array}$ & $\begin{array}{l}\mathrm{PM}_{10} \\
\left(\mu \mathrm{g} \mathrm{m}^{-3}\right)\end{array}$ & $\begin{array}{c}\mathrm{PM}_{10} \\
\text { National } \\
\text { standard } \\
\left(\mathrm{\mu g} \mathrm{m}^{-3}\right)\end{array}$ \\
\hline Booysens & Central-West & 3 & \multirow{5}{*}{19} & 51 & \multirow{5}{*}{50} \\
\hline Mamelodi & East & 5 & & 86 & \\
\hline Olievenhoutbosch & South & 5 & & 92 & \\
\hline Pretoria West & Central-West & 24 & & 67 & \\
\hline Rosslyn & North & 16 & & 35 & \\
\hline
\end{tabular}

Note. Frequency of permissible exceedances per year: 0 for $\mathrm{SO}_{2}$ and 0 for $\mathrm{PM}_{10}$. Data included in this calculation span 1 January 2009 to 31 December 2009 and were provided by SAAQIS.

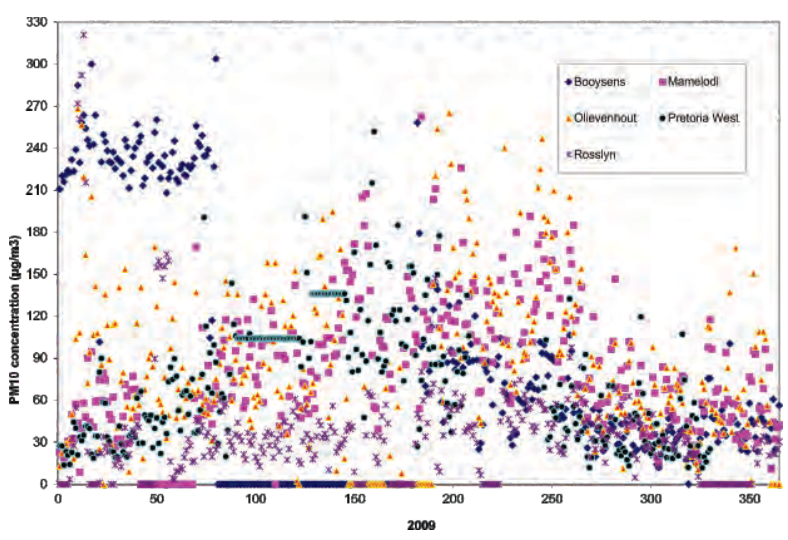

Figure 5. Daily average $\mathrm{PM}_{10}$ concentrations for all permanent $A Q$ monitoring stations in Tshwane.

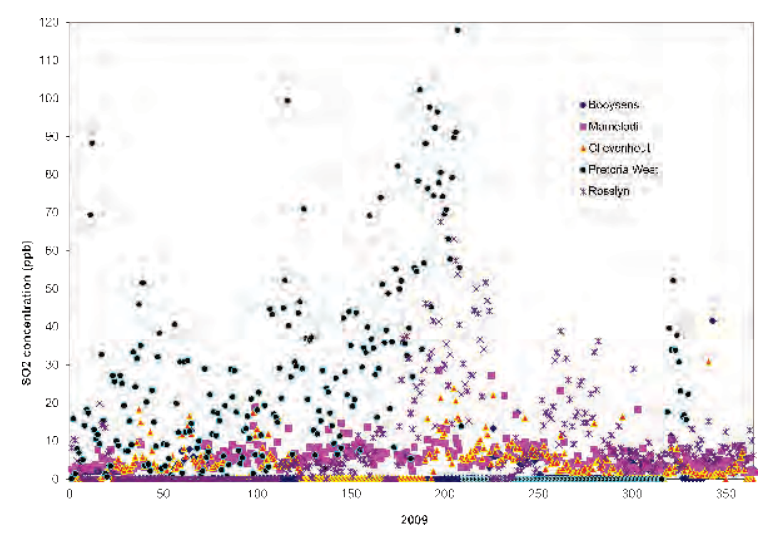

Figure 6. Daily average $\mathrm{SO}_{2}$ concentrations for all permanent $A Q$ monitoring stations in Tshwane. 
Table 2. Type of air-related complaint by region and nearest permanent $A Q$ monitoring station, with $\mathrm{SO}_{2}$ and $\mathrm{PM}_{10}$ daily average concentrations for National Ambient Air Quality Standards exceedances only.

\begin{tabular}{|c|c|c|c|c|c|}
\hline & & & & \multicolumn{2}{|c|}{ Exceedance values (bold) } \\
\hline $\begin{array}{l}\text { Date in } \\
2009\end{array}$ & Region & AQ Station & Complaint type & $\begin{array}{c}\text { Measured } \mathrm{SO}_{2} \\
\text { 24-hour } \\
\text { average } \\
\text { concentration } \\
\text { (ppb) }\end{array}$ & $\begin{array}{c}\text { Measured } \mathrm{PM}_{10} \\
\text { 24-hour average } \\
\text { concentration } \\
\left(\mu \mathrm{g} \mathrm{m}^{-3}\right)\end{array}$ \\
\hline 2 March & Central-West & Booysens & Backyard fires & 5.09 & 215.61 \\
\hline 28 May & East & Mamelodi & Backyard fires & 7.27 & 144.62 \\
\hline 23 July & East & Mamelodi & Dust & 6.72 & 225.91 \\
\hline 13 August & East & Mamelodi & Dust & 27.33 & 161.98 \\
\hline 20 August & East & Mamelodi & Dust & 22.00 & 180.00 \\
\hline 18 February & South & Olievenhoutbosch & Backyard fires & 2.50 & 169.42 \\
\hline 1 September & South & Olievenhoutbosch & Dust & 6.56 & 224.99 \\
\hline 1 September & South & Olievenhoutbosch & Odour & 6.56 & 224.99 \\
\hline 28 January & Central-West & Pretoria West & Fumes & 159.94 & 27.23 \\
\hline 15 April & Central-West & Pretoria West & Undefined & 7.20 & 190.63 \\
\hline 8 July & Central-West & Pretoria West & $\begin{array}{l}\text { Spray-painting } \\
\text { gasses }\end{array}$ & 33.29 & 156.91 \\
\hline 20 July & Central-West & Pretoria West & $\begin{array}{l}\text { Spray-painting } \\
\text { gasses }\end{array}$ & 48.78 & 124.53 \\
\hline 22 July & Central-West & Pretoria West & Fumes & 36.12 & 184.79 \\
\hline 28 July & Central-West & Pretoria West & Dust & 35.12 & 155.67 \\
\hline 14 August & Central-West & Pretoria West & Backyard fires & 92.29 & 91.27 \\
\hline 23 February & North-West & Rosslyn & Odour & Missing & 155.48 \\
\hline 25 February & North-West & Rosslyn & Dust & Missing & 159.59 \\
\hline
\end{tabular}

Note. $\mathrm{PM}_{10}$ daily exceedance limit $=120 \mu \mathrm{g} \mathrm{m}^{-3} . \mathrm{SO}_{2}$ daily exceedance limit $=48 \mathrm{ppb}$ (Immediate effect until 31 December 2014; from 1 January 2015, $\mathrm{PM}_{10}$ daily exceedance limit $\left.=75 \mu \mathrm{g} \mathrm{m}^{-3}\right)(\mathrm{RSA}, 2009)$.

Air-related complaints in relation to monitored ambient $A Q$ concentrations

During 2009, there were a total of 86 air-related complaints for which $A Q$ data from the nearest permanent $A Q$ monitoring station were available. The greatest number of complaints were made during the winter months of June, July and August ( $n=27$ : North, $n=8$; CentralWest, $n=10$; East, $n=7$; and South, $n=2$ ). A similar number of complaints were made during summer (December, January and February), autumn (March, April and May) and spring (September, October and November), i.e. $n=20$, $n=22$ and $n=17$, respectively. Of these, there were three days with air-related complaints when the 24-hour standard for $\mathrm{SO}_{2}$ was exceeded and 15 days when the 24-hour standard for $\mathrm{PM}_{10}$ (Table 2) was exceeded.

The three $\mathrm{SO}_{2}$ daily exceedances of $48.7 \mathrm{ppb}$ (slight exceedance), $92.2 \mathrm{ppb}$ (moderate exceedance) and $159.9 \mathrm{ppb}$ (high exceedance) were all recorded in the Central-West regional zone. Of the 15 exceedances of the daily $\mathrm{PM}_{10}$ standard, 5 were recorded at the Pretoria West $A Q$ monitoring station (Central-West zone) and 4 were recorded at the Mamelodi $A Q$ monitoring station (East zone). Nine of these $A Q$ exceedances for days when air-related complaints were lodged occurred during winter and early spring.

The daily average air pollutant concentrations on days when complaints were made by residents 
in the two zones with the greatest number of airrelated complaints during 2009, i.e. CentralWest and East, are shown in Figures 7 and 8 , respectively. There was no pattern or correlation between the two air pollutants' daily average concentrations on complaint days in the CentralWest $\left(R^{2}=0.026\right)$ and the East $\left(R^{2}=0.3223\right)$ zones.

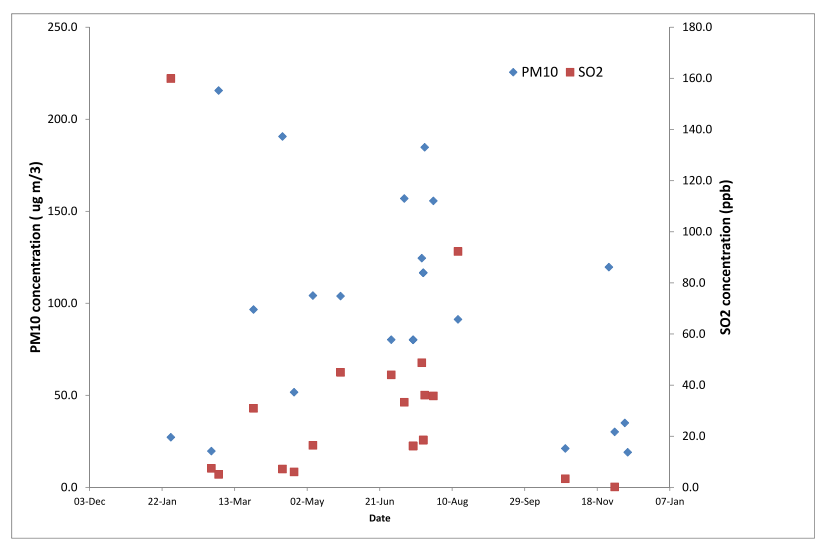

Figure 7. Daily average $\mathrm{PM}_{10}$ and $\mathrm{SO}_{2}$ concentrations for those days when air-related complaints were made by the public for the Central West zone in Tshwane during $2009(n=23)$.

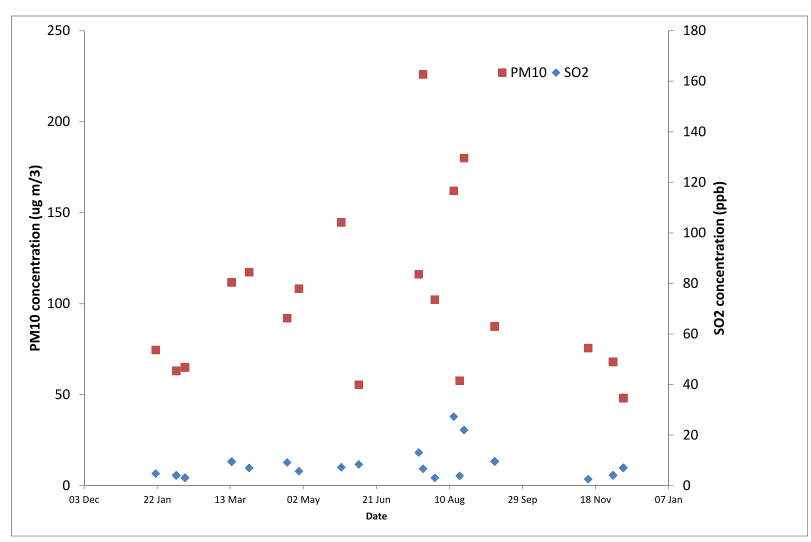

Figure 8. Daily average $\mathrm{PM}_{10}$ and $\mathrm{SO}_{2}$ concentrations for those days when air-related complaints were made by the public for the East zone in Tshwane during 2009 ( $n=25)$.

\section{Discussion}

Under new $A Q$ legislation, South African local authorities are now responsible for $A Q$ management. This trend of role decentralisation is common in several countries, including the United States (NRC, 2004), the United Kingdom and some European countries (Elsom, 1999). Most of these local authorities have developed and implemented air quality management plans which mention 'exposure assessment' in the suite of activities described in the plan. Efforts to intervene and improve $A Q$ include, for example, continuous $A Q$ monitoring and the introduction of Atmospheric Emission Licences (RSA, 2010) replacing the permits under APPA. However, no system for 'exposure assessment', either perceived experience or impact, or human health effects, such as air-related health surveillance, has been developed or implemented to consider whether the communities' experience of $A Q$ may improve as air pollution is reduced. The only routinely-monitored 'quasi-indicator' of the impact of $A Q$ on people is the 'air-related complaint'. Using 5 years of air-related complaints lodged by the public living in the City of Tshwane, this article explored the applicability and usefulness of using air-related complaints as an indicator of the public's experience of $A Q$ on the public. It is well known that air pollution exposure is related to several adverse health effects, however, obtaining accurate, up-to-date and comprehensive health data for a specific location in a developing country to analyse trends is fraught with challenges and difficulties. Using the presently applied air-related complaints indicator as an example, it was seen that it is possible to routinely collect potentially useful information; however, this particular indicator is not optimized fully to elucidate a complete understanding of the public's experience of air pollution or suggest possible human health effects other than a nuisance effect that may impact on quality of life.

A total of 875 complaints were made during the 5year period, i.e. 2005-2009. This is relatively few given that the population size of the metropolitan area estimated at 1985983 in 2001 (City of Tshwane, 2004). Access to a telephone, the correct telephone number for Municipal Health Services and willingness to lodge a complaint, are important factors influencing the likelihood of a complaint being made and successfully captured by the EHPs.

Over all, the most number of complaints were made about open fires. The Environmental Management Division recently initiated the 'Follow the Smoke' campaign. The aim of this programme is to attend to as many sighted smoke events as soon as possible. Particular emphasis is placed on cable and tyre burning, illegal open fires and veld fires. Complaints about spray-painting fumes were also common, most probably since the main air pollutants emitted are volatile organic compounds (VOCs) which have a strong odour. Dust was also frequently reported and most likely came from unsealed roads, open and non-vegetated plots and industrial and construction activities. Since the 
City of Tshwane classification of complaint was retained during these analyses, it was not possible to define the difference between open fires and backyard fires; however, it was assumed that all backyard fires were contained within the boundaries of a property.

Spatially, the Central-West and East zones had the most number of complaints. These zones are densely populated, particularly when compared to the North-East zone, and this may have contributed to their total number of complaints. There was no specific type of complaint regularly made in a particular zone, most likely since the mix of type and number of industries and homes is similar across all regional zones, expect for the presence of a coal-fired power station and a cement factory in the in the Central-West Zone. In the East zone, there is a large settlement of formal and informal housing (Mamelodi) where residents burn solid fuel for heating during winter months. Further evidence of the impacts of these domestic and industrial influences across Tshwane was apparent from the $A Q$ analyses.

The $A Q$ monitoring station in Pretoria West consistently showed the highest $\mathrm{SO}_{2}$ levels compared to all of the monitoring stations in Tshwane (Figure 5). Sources in the vicinity of this station that might have had an influence on the pollution levels are the coal-fired power station as well as informal communities. Given the prevailing wind direction (i.e. North-East) for the area, as measured at the Pretoria Eendracht meteorological station from 1993 to 2008, domestic coal burning in Mamelodi may have also contributed to these ambient $A Q$ conditions. The exceedances at the Rosslyn AQ monitoring station occurred during mid-winter. Reasons for this phenomenon were most probably inversion layers and an increase in domestic coal burning. Although, as mentioned above, since the annual wind rose showed the prevailing wind to be from the North East, it is possible that the wind direction may have differed during the winter months. Should this be the case and the wind direction was more North and North West during winter, domestic fuel burning in two low income communities, namely, Ga-Rankuwa and Soshanguve, might also have had an influence on the $\mathrm{SO}_{2}$ levels at the Rosslyn AQ monitoring station. Another possible source may include a cement factory in the area, depending on whether this industry makes use of coal burning, and a coal-fired power station in Rooiwal. It is known that these pollutants are emitted from the stacks at a high level, but depending on dispersion, climate and topography, these pollutants may deposit at the Rosslyn AQ station at the other side of the mountain that dissects the City of Tshwane in a West-East orientation.

For $\mathrm{PM}_{10}$, the Booysens $\mathrm{AQ}$ monitoring station recorded the most number of exceedances $(n=$ 85) for 2009. Most of the exceedances at Booysens happened during the first two months of 2009 , thus not during winter when inversion layers and an increase in domestic fuel use are expected. Two possible explanations could be either upset conditions at a single source such as a start-up after the December holidays or the $A Q$ monitoring station was malfunctioning, which could be the reason for not recording any $\mathrm{PM}_{10}$ concentrations directly following the peak. The latter explanation is difficult to ascertain given that levels recorded at the other stations also showed peaks during early 2009 , however, this cannot be determined without further information and a better understanding of local conditions.

The objective of this study was not to pinpoint likely air pollution sources in relation to ambient $A Q$. Instead, it was to consider ambient $A Q$ in the vicinity of the complainant as an indicator of the impact of $A Q$ at the time when the complaint was made. When air-related complaints were considered in conjunction with ambient $A Q$, several challenges arose. There was not always a permanent $A Q$ monitoring station near to the complainant's suburb of residence; hence the nearest $A Q$ monitoring station was used as a proxy. The predominant wind direction for the day of the complaint was considered, qualitatively, to assess the validity of this approach, however, no data were disregarded because wind speed and topography also play a part in air pollution dispersal. In future, this could be considered using $A Q$ modelling and with additional data sources as input to the models. The two air pollutants with consistent data streams at all permanent monitoring stations were $\mathrm{SO}_{2}$ and $\mathrm{PM}_{10}$. However, $\mathrm{SO}_{2}$ and $\mathrm{PM}_{10}$ concentrations were not always representative of the types of air pollutants associated with airrelated complaints. For example, spray-painting fumes are likely to comprise mainly VOCs (Donohue et al., 1996). Air pollution from open fires and backyard fires is likely to be particulates, $\mathrm{SO}_{2}$ and VOCs when tyres are burnt (Murray and McGranahan, 2003). Dust and smoke are most likely particulate pollution (Murray and McGranahan, 2003). Future research should attempt to use the specific types of air pollutants, where monitored, and relevant to the complaint. For this study, $\mathrm{SO}_{2}$ and $\mathrm{PM}_{10}$ concentrations were investigated. Furthermore, it was assumed that if the concentrations of these two most common air pollutants were high, then 
the ambient $A Q$ was possibly perceived by the public as being poor too due to the odour and impact on visibility of $\mathrm{SO}_{2}$ and $\mathrm{PM}_{10}$, respectively. This relates to a recent trend to manage $A Q$ in a progressively 'multipollutant' manner by controlling as many air pollutants as possible in an integrative way for the greatest total reduction of adverse human health effects (Mauderly et al., 2010).

When considering exceedances of the National Ambient Air Quality Standards, there were 17 complaint days with either an $\mathrm{SO}_{2}$ or $\mathrm{PM}_{10}$ daily average concentration exceedance. Of these, it is unlikely that complaint cases 'match' the monitored ambient $\mathrm{SO}_{2}$ and $\mathrm{PM}_{10}$ daily average concentrations monitored, for reasons mentioned above. In some instances, there were exceedances of the $\mathrm{PM}_{10}$ standard at the nearest $A Q$ monitored station on a day that a complaint about backyard or open fires was made, however, without additional data (not always available) and atmospheric modelling (expensive and time consuming), it is not possible to validate these findings. Since the purpose was to consider practical ways for local authorities to track the impact of $A Q$ on the public, these options are consider nonviable.

It is evident from the monitoring data that air pollution in Tshwane, especially $\mathrm{PM}_{10}$, is a concern and the situation is worst during winter months. Presently, the only routinely-collected indicator of the possible impact of air pollution on the public is air-related complaints lodged by residents of the City to Municipal Health Services. It may be useful to record health symptoms experienced by the complainant with the air-related complaint. However, there is a real need to have local, air-related health data, for example, upper and lower respiratory tract infections, asthma, etc, generated at clinics and hospitals delivered directly and on an on-going, continuously updated basis to Municipal Health Services of the City of Tshwane. This would allow for long-term trend analyses as well as acting as an early warning system and way to identify air pollution hotspots.

\section{Conclusions}

It is very difficult to make meaningful conclusions about the relation between $A Q$ and air-related complaints with the current number of $A Q$ monitoring stations, air pollutants consistently measured, available $A Q$ data and information captured when an air-related complaint is logged. However, the aim of this study was not to try and show an increase in the number of air- related complaints with increasing ambient air pollution. Several residents in the City of Tshwane may not be aware that they can lodge an air-related complaint or they may not know the correct Management Division with whom to lodge the complaint for official records and formal follow-up. Many residents may not have access to a telephone or the correct, up-to-date telephone 'hotline' number. Some residents may experience air pollution but apathy prevents them from lodging an official complaint. Given these social and economic constraints, as well as data and other challenges, it does not seem feasible to use air-related complaint as an indicator of the public's perceptions or experiences of ambient $A Q$. Instead, citizen complaints should be complimentarily when describing air quality impacts on the public, together with local, air-related health data, towards integrative public health surveillance in air quality management.

\section{Acknowledgements}

This project was funded by a Council for Scientific and Industrial Research Young Researchers Establishment Fund grant. Mogesh Naidoo of the Atmospheric Modelling Strategic Initiative, CSIR Natural Resources and the Environment (Durban) for GIS support. Municipal Health Services and Environmental Management Division of the City of Tshwane are thanked for provision of data and valuable information.

\section{References}

Brook RD, Rajagopalan S, Pope III AC, Brook JR, Bhatnagar A, Diez-Roux AV, Holguin F, Hong Y, Luepker RV, Mittleman MA, Peters A, Siscovick D, Smith Jr SC, Whitsel L, Kaufman JD (2010) Particulate Matter Air Pollution and Cardiovascular Disease: An Update to the Scientific Statement From the American Heart Association. Circulation 121: 2331-2278.

Cadman A, Dames JF, Terblanche PS, Nel R (1997) The AIRKEM study in Gauteng, South Africa. The role of the airspora in an industrial urban environment. Grana 36:175-179.

City of Tshwane 2004. Tshwane Metropolitan Profile A Compendium of Planning Information. City of Tshwane Metropolitan Municipality Department of Housing, City Planning and Environmental Man a g e ment

http://www.tshwane.gov.za/documents/Metropolitan Profile080305.pdfAccessed 24 November 2010.

Cohen AJ, Pope $3^{\text {rd }}$ CA (1995) Lung cancer and air pollution. Environ Health Perspect 103(8): 219-224.

Donohue MD, Geiger JL, Kiamos AA, Nielsen KA 
(1996) Reduction of volatile organic compound emissions during spray painting: A new process using supercritical carbon dioxide to replace traditional paint solvents. Green Chemistry, ACS Symposium Series, Vol 626. chapter 12, pp 152-167.

Klaeboe $\mathrm{R}$, Kolbenstvedt $\mathrm{M}$, Clench-Aas $\mathrm{J}$, Bartonova A (2000) Oslo traffic study - part 1: an integrated approach to assess the combined effects of noise and air pollution on annoyance. Atmospheric Environment 34:4727-4736.

Dasgupta S, Wheeler D (1996) Citizen complaints as environmental indicators: evidence from China. Environment, Infrastructure and Agriculture Division, Policy Research Development, World Bank.

Elsom DM (1999) Development and implementation of strategic frameworks for air quality management in the UK and the European Community. J Env Plan and Man 42(1):103-121.

Evendijk JE, Muskens PJWM, De Jong TJRM (1980) Relationship between citizen complaints of air pollution, meteorological data and emission concentrations. Studies in Env Science 8:379-386.

Koenig JQ (1999) Air pollution and asthma. J Allergy and Clin Immunol 104(4):717-722.

Krzyzanowski M, Cohen A (2008) Update of WHO air quality guidelines. Air Qual Atmos Health 1:7-13.

Mauderly JL, Burnett RT, Castillejos M, Ozkaynak H, Samet JM, Stieb DM, Vedal S, Wyzga RE (2010) Is the air pollution health research community prepared to support a multipollutant air quality management framework? Inhalation Toxicology 22(S1):1-19.

Murray F, McGranahan G (2003) Introduction: Air pollution and Health in Developing Countries - The Context. In McGranahan G, Murray F (eds) Air Pollution and Health in Developing Countries. Earthscan Publications Ltd, London, pp 1-15.

National Research Council (NRC) (2004) Air quality management in the United States. The National Academies Press, Washington.

Pan G, Zhang S, Feng Y, Takahashi K, Kagawa J, Yu L, Wang P, Liu M, Liu Q, Hou S, Pan B, Li J (2010) Air pollution and children's respiratory symptoms in six cities of Northern China. Respiratory Medicine 104:1903-1911.

Republic of South Africa (RSA) (1965) The Atmospheric Pollution Prevention Act (Act Number 45 of 1965). Government Printer, Pretoria.

Republic of South Africa (RSA) (2003) National Health Act (Act Number 61 of 2003). Government Printer, Pretoria.

Republic of South Africa (RSA) (2004) National Environmental Management: Air Quality Act (Act No. 39 of 2004). Government Printer, Pretoria.
Republic of South Africa (RSA) (2009) National Environmental Management: Air Quality Act (Act No. 39 of 2004) National Ambient Air Quality Standards. Government Gazette No. 32816. Government Printer, Pretoria.

Republic of South Africa (RSA) (2010) National Environmental Management: Air Quality Act (AQA) (Act No. 39 of 2004) List of activities which result in atmospheric emissions which have or may have a significant detrimental effect on the environment, including health, social conditions, economic conditions, ecological conditions or cultural heritage. Government Gazette No. 33064. Government Printer, Pretoria.

WHO 2005 Air Quality Guidelines Global Update Report Number EUR/05/5046029. WHO, Geneva. 